\title{
COMMENT
}

\section{Short-term scholar visas are essential for science}

\author{
Kauê M. Costa $\mathbb{D}^{1}$ and Ayesha Sengupta $\mathbb{D}^{1}$ \\ Neuropsychopharmacology (2021) 46:277-278; https://doi.org/10.1038/s41386-020-00880-9
}

The recent (June 22nd) presidential proclamation suspending short-term work visas, including the $\mathrm{H}-1 \mathrm{~B}$ and certain categories of J-1 programs [1], has created significant distress among the community of visiting scholars in the USA. As participants in the J1 program, we would like to voice our concerns about what we believe to be a misguided policy. There are legitimate issues regarding the exploitation of short-term work visas and their recipients that should be addressed specifically, and while J-1 research scholars (the category encompassing most US postdoctoral researchers) are currently exempt from the proclamation, many scientists will still be affected.

The USA is ranked first in the world in scientific output but is closely followed by countries like China, Germany, the UK and Japan. Suspending temporary visa programs for scientists severely affects scientific enterprise in the USA, where it is estimated that over half of post-doctoral scientists, the cornerstone of the research workforce, are temporary visa holders [2]. The problems that this proclamation creates are manifold.

(1) Scientific work is highly specialized, and sometimes there are only a handful of people in the world that have the expertise to apply certain experimental or theoretical methods. Sometimes these people are not in the US and bringing them in as visiting scholars allows for the transfer of crucial knowledge to American laboratories. Limiting this exchange of expertise severely restricts the capacity of American work groups to absorb new methods developed abroad.

(2) Visiting scholars often bring their own funding from their countries of origin, and therefore also represent a direct net financial gain for the country. This is in addition to the indirect gain obtained by absorbing the expertise of people who have received several thousands of dollars' worth of education and training in other countries.

(3) There is empirical evidence that the impact of research by foreign-born scientists is on average higher than that of locals who have no international mobility experience, even when accounting for differences in relative career positions in their countries of origin [3]. Also, studies show that diverse research groups, which are often characterized by international members, tend to publish more frequently and are cited more often [4]. These groups benefit from the range of ideas and perspectives that are essential for the innovative thinking that drives scientific advancement. This indicates that there is a gain in research quality to be obtained from international cooperation that cannot be replaced by quickly substituting visiting scientists with locals.
(4) Moving to another country takes a substantial financial, logistic and emotional toll on visiting scholars. Scientists who choose to do this often must relocate their families, be separated from friends and loved ones, learn a new language and deal with varying levels of bureaucratic hurdles. Due to emergencies, they may also need to travel abroad without much warning. Adding another barrier to this process just increases the burden inherent to these circumstances. Even though the new policy is temporary and does not immediately affect visiting researchers currently in the US, there is now a growing concern that harsher measures might be implemented in the near future. The lack of security this creates will likely dissuade many foreign scholars from uprooting their lives to work in the USA. Instead, many scientists are already choosing to pursue positions elsewhere. Other countries, such as Germany, France and China, have recently increased their efforts to attract foreign scientists $[5,6]$, for instance by offering permanent residency status for visitors with $\mathrm{PhDs}$ who secure certain positions. The June 22nd proclamation therefore reduces the ability of US labs to attract highly qualified personnel who can otherwise secure positions in other countries.

(5) The proclamation causes unnecessary distress not only for the visiting scholar community but also for their American colleagues and group leaders who rely on their work for the continuation of their research, which is only exacerbated by the current disruption imposed by the COVID-19 pandemic.

In closing, we urge the current administration and all relevant policy makers to reconsider this course of action, and we request that all members of the academic community express the importance of these visa programs to the general public and to their government representatives. Though temporary, the enacted suspensions may lead to a long-term disruption of scientific research in the US, much of which is crucial for public health and technological advancement. The resulting exodus of scientific talent to other industrialized nations could directly damage the nation's leading scientific research and higher education institutions for years to come.

\section{FUNDING AND DISCLOSURE}

No significant funding was received for work on this manuscript. The authors declare no competing financial interests in relation to the work described

\footnotetext{
Baltimore, MD, USA

Correspondence: Kauê M. Costa (kaue.m.costa@gmail.com)
}

Received: 19 August 2020 Revised: 14 September 2020 Accepted: 17 September 2020

Published online: 16 October 2020 


\section{AUTHOR CONTRIBUTIONS}

KMC and AS conceptualized and wrote the manuscript.

\section{ADDITIONAL INFORMATION}

Publisher's note Springer Nature remains neutral with regard to jurisdictional claims in published maps and institutional affiliations.

\section{REFERENCES}

1. Proclamation suspending entry of aliens who present a risk to the U.S. labor market following the coronavirus outbreak. The White House. https://www. whitehouse.gov/presidential-actions/proclamation-suspending-entry-aliens- present-risk-u-s-labor-market-following-coronavirus-outbreak/. Accessed 23 June 2020

2. nsf.gov - Table 1-3b - NCSES survey of graduate students and postdoctorates in science and engineering, 1972-2018: Fall 2018 - US National Science Foundation (NSF). https://ncsesdata.nsf.gov/gradpostdoc/2018/html/gss18-dt-tab001-3b.html. Accessed 23 June 2020.

3. Scellato G, Franzoni C, Stephan P. A mobility boost for research. Sci 2017;356:694.

4. Powell K. The power of diversity. Nature 2018;558:19-22.

5. Foreign-born scientists find a home in China | Science | AAAS. https://www. sciencemag.org/features/2016/11/foreign-born-scientists-find-home-china. Accessed 23 June 2020.

6. Several countries launch campaigns to recruit research talent from U.S. and elsewhere. https://www.insidehighered.com/news/2017/07/26/several-countries-launchcampaigns-recruit-research-talent-us-and-elsewhere. Accessed 23 June 2020. 